\title{
The Impact of Gratitude on Core Self-Evaluations of Rural Junior Middle School Students: A Chain Mediation Analysis
}

\author{
Xiaozhou Zhang1, Jie Luo², Ting Peng', Yun Hong1, Xiaoyan Li ${ }^{4}$ \\ ${ }^{1}$ School of Education, Tongren University, Tongren, China \\ ${ }^{2}$ School of Psychology, Guizhou Normal University, Guiyang, China \\ ${ }^{3}$ Humanities Foundation Department, Guizhou Health Vocational College, Tongren, China \\ ${ }^{4}$ School of Psychology, Northwest Normal University, Lanzhou, China \\ Email: xiaozhouedu@163.com
}

How to cite this paper: Zhang, X. Z., Luo, J., Peng, T., Hong, Y., \& Li, X. Y. (2020). The Impact of Gratitude on Core Self-Evaluations of Rural Junior Middle School Students: A Chain Mediation Analysis. Psychology, 11, 1141-1152. https://doi.org/10.4236/psych.2020.118075

Received: July 13, 2020

Accepted: August 16, 2020

Published: August 19, 2020

Copyright $\odot 2020$ by author(s) and Scientific Research Publishing Inc. This work is licensed under the Creative Commons Attribution International License (CC BY 4.0).

http://creativecommons.org/licenses/by/4.0/

\begin{abstract}
Objective: To explore the mediating effects of self-esteem and academic self-efficacy on gratitude and core self-evaluations in rural junior middle school students. Methods: The Gratitude Scale, Self-esteem Scale, Academic Self-Efficacy Scale and Core Self-Evaluations Scale were used to conduct a questionnaire survey among 923 rural junior middle school students. The bias-corrected percentile Bootstrap method was conducted to test the chain mediating role of self-esteem and academic self-efficacy between rural junior middle school students' gratitude and core self-evaluations. Results: Correlation analysis showed significantly positive correlations between gratitude, self-esteem, academic self-efficacy and core self-evaluations $(r=0.30-0.56, P$ $<0.01)$; the mediation model indicated that gratitude had a significant direct effect on core self-evaluation, with an effect value of 0.094 and accounting for $21.91 \%$. The mediating role of self-esteem and academic self-efficacy between gratitude and core self-evaluations was significant, with effect values of 0.225 and 0.027 , accounting for $52.45 \%$ and $6.29 \%$, and the chain mediating role of self-esteem and academic self-efficacy in rural junior middle school students' gratitude and core self-evaluations was also significant, with an effect value of 0.083 and accounting for $19.35 \%$. Conclusion: Gratitude not only directly influences the core self-evaluations of rural junior middle school students, but also through the indirect path of self-esteem and academic self-efficacy, as well as the chain mediating path between these two variables.
\end{abstract}

\section{Keywords}

Rural Junior Middle School Students, Gratitude, Self-Esteem, Core Self-Evaluations, Academic Self-Efficacy 


\section{Introduction}

Core self-evaluations, as a personality concept, refer to the basic evaluations and attitudes of individuals on their abilities and self-worth. It is usually composed of four traits: self-esteem, general self-efficacy, neuroticism and control points (Judge et al., 1998), which has the significant impact on individual mental health and behavior (Luo et al., 2019). Previous studies have suggested that the people who have the higher core self-evaluations levels are more likely to feel positive emotions (e.g., happiness, life satisfaction) rather than negative emotions (e.g., anxiety, depression) (Sudha, 2013). They are full of confidence of life, purse goals consistent with their own values (Judge \& Larsen, 2001), and then well adapt to the development of society (Lv \& Zhou, 2019). Junior middle school students are in a critical period of whole process of individual development, which their physical and mental conditions are undergoing complex and drastic changes (Lin, 2008). More specially, for the rural junior middle school students, which their parents are working as a labourer in urban area, may easily lead to single understanding of self-ability and self-worth for the deficiency of parental companionship and emotional support (Yang, Yi, \& Song, 2016). As one of the positive psychological resources, the core self-evaluation is a kind of overall self-evaluation, which will affect personalities, interpersonal relationships, life satisfactions and other aspects of rural junior middle school students (Guo \& Ye, 2017). It plays an important role to guide rural junior middle school students to correctly understand their self-ability and self-worth in their growth and development. Therefore, exploring the core self-evaluation of rural junior middle school students with its influencing factors is conducive to providing guidance and reference for rural junior middle school students, helping them adapt to their school lives, develop their academic levels, and promote the development of their mental health.

Gratitude, also as a hot topic of positive psychology research, refers to an individual psychological tendency responding to the kindness and helps from others through gratitude cognition, emotions, and behaviors to obtain positive experiences or results. It is positively associated with optimism, happiness, life satisfaction and prosocial behavior (Wu et al., 2019), which can broaden the individuals' cognition and behavior, improve the interaction mode between individuals and the external environment, and promote the overall development of people (Fredrickson, 2001). In particular, the cultivation of adolescents' gratitude qualities can help to enhance their personality development, cultivate social responsibility, and improve national cohesion, which is of great significance to the advancement of Chinese socialist harmonious construction (Wen et al., 2010). Existing studies have shown that there is a significant positive correlation between gratitude and core self-evaluations. Individuals with a high level of gratitude are contributing to increasing positive awareness of self, others, and the world. It can also enhance individuals ability to cope with frustration and social adaptation, which helps to form positive self-evaluation. Based on the above, we 
put forward the 1 hypothesis that gratitude can significantly predict the core self-evaluations of rural junior middle school students and it is necessary to investigate the underlying mechanism between gratitude and core self-evaluations.

Self-esteem, which is the main component of self-structure, refers to the positive or negative attitude of an individual towards the worth of self. It is a complex psychological trait that includes competence and sense of value (Zhang, Li, \& Yu, 2019), reflecting the degree of individual recognition and appreciation of themselves (Abdollahi \& Talib, 2015). Individuals with high self-esteem have strong emotion control ability and adaptability. They are enthusiastic and generous in their life, and often greet new things with a positive attitude (Baumeister et al., 2003), which have a positive influence towards their cognition, motivation, emotions and social behavior, making individuals more willing to pursue the meaning of real life (Lee \& Jung, 2014). Previous studies have shown that there is a significant positive correlation between self-esteem and core self-evaluations (Wang, Liu, \& Jackson, 2016), to be specific, the higher the self-esteem level, the more positive the self-esteem and self-confidence they have, and the more reasonable self-identification and positive self-evaluation they own. At the same time, studies have also indicated that there is a significant correlation between individual gratitude and self-esteem (Li et al., 2011). Developments of the levels of gratitude are conducive to establishing a positive cognitive model and a good interactive relationship with others, thereby helping to form a correct understanding of themselves (Hou, 2019), and further promoting the development of their self-esteem. Based on the above, we put forward the 2 hypothesis that self-esteem has a mediating effect between gratitude and core self-evaluations in rural junior middle school students.

Academic self-efficacy, as an vital influencing factor for individual academic achievement, refers to the belief and judgment of an individual whether is capable of completing a certain task in the academic field (Zimmerman, 1995), including academic behavior self-efficacy and ability self-efficacy. Its development has an important influence on individual learning motivation, and exerts an important protective effect on individual mental health (Wu, Liu, \& Gao, 2017). Individuals with higher academic self-efficacy are more likely to develop positive learning qualities (Liu, 2017), and have confidence in their work and learning. They will be willing to make various attempts to from diverse learning behaviors (Qi \& Wei, 2016). Existing studies have shown that there is a significant positive correlation between self-efficacy and core self-evaluations (Zhou \& Han, 2014). Because the academic self-efficacy belongs to a specific area of self-efficacy (Chen, 2016), by parity of reasoning, it can be inferred that there is a significant correlation between academic self-efficacy and core self-evaluations. That is, when individuals have the ability to complete their own learning tasks, their confidence level will increase, accompanying with their core self-evaluations will be improved. Additional, gratitude is significantly related to academic self-efficacy $(\mathrm{Xu}, 2019)$. According to expansion effect of gratitude, gratitude will help individuals to experience more love and support, enhance their cognition, enrich 
their thinking style, and gradually internalize them into habits, thus improving their academic self-efficacy (Fredrickson \& Talib, 2002). Based on this, hypothesis 3 is that there is a mediating effect of academic self-efficacy between gratitude and core self-evaluations in rural junior middle school students. In addition, self-esteem is significantly related to academic self-efficacy (Zhou, 2019). That is, individuals with high self-esteem can face with learning difficulties and challenges with a more positive attitude in the learning process, and show a strong sense of academic self-efficacy. This study proposes hypothesis 4 based on the above analysis that self-esteem and academic self-efficacy play a chain mediating role between gratitude and core self-evaluations in rural junior middle school students.

\section{Participants and Methods}

\subsection{Participants}

Participants were selected from 6 rural middle schools from Gansu province and Guizhou province in China. With the cooperation and help of the class teacher, we carry out the collective test and collect the questionnaire on the spot. In the survey, 1000 questionnaires were distributed; the valid sample included 923 rural junior middle school students, with an effective rate of $92.3 \%$, of which were 468 females $(50.71 \%)$ and 455 males (49.29\%). There were 321 seventh graders (34.77\%), 310 eighth graders (33.59\%), and 292 ninth graders (31.64\%). Participants age ranged from 11 to 18 years with a mean age of $14.13(S D=1.19)$.

\subsection{Measures}

\subsubsection{Gratitude Questionnaire-6 Scale}

The scale consists of 6 items (Wei et al., 2011). On this scale, the participants reported the degree to which they agreed with each of the items from 1 (strongly disagree) to 7 (strongly agree). The higher the score, the higher the level of individual gratitude. The Cronbach's a reliability coefficient was 0.70 .

\subsubsection{Self-Esteem Scale}

The scale consists of 10 items (Yang \& Wang, 2007). On this scale, the participants reported the degree to which they agreed with each of the items from 1 (strongly disagree) to 4 (strongly agree). The higher the score, the higher the level of individual self-esteem. The Cronbach's a reliability coefficient was 0.76 .

\subsubsection{Academic Self-Efficacy Scale}

The scale consists of 18 items (Zeng, 2008). On this scale, the participants reported the degree to which they agreed with each of the items from 1 (strongly disagree) to 5 (strongly agree). The higher the score, the higher the level of individual academic self-efficacy. The Cronbach's a reliability coefficient was 0.88 .

\subsubsection{Core Self-Evaluations Scale}

The scale consists of 10 items (Dai, 2010). On this scale, the participants reported the degree to which they agreed with each of the items from 1 (strongly 
disagree) to 5 (strongly agree). The higher the score, the higher the level of individual core self-evaluations. The Cronbach's a reliability coefficient was 0.72 .

\subsection{Dates Analysis}

SPSS21.0 was used for descriptive statistics, reliability and correlation analysis of the current study, and SPSS macro process program compiled by Hayes was used for mediating effect test.

\section{Results}

\subsection{Common Method Bias Test}

The study applied the Harman's single factor method proposed to test the common method bias (Zhou \& Long, 2004). Exploratory factor analysis of all variables showed that the total of 9 common factors with initial eigenvalues greater than the first common factor, and it could explain $22.13 \%$ of the total variance, less than $40 \%$. There was not significant common method bias in the measurement.

\subsection{Descriptive Statistics and Correlation Analysis}

The correlation between gratitude, self-esteem, academic self-efficacy and core self-evaluations was analyzed. The results showed that there was a significant positive correlation between gratitude, self-esteem, academic self-efficacy and core self-evaluations, the result as shown in Table 1.

\subsection{The Influence of Gratitude on Core Self-Evaluations: The Chain Mediated Effect Test}

According to the mediating effect test method (Wen \& Ye, 2014), the mediating effect of self-esteem and academic self-efficacy between gratitude and core self-evaluations of rural junior middle school students was tested after controlling for gender and grade, the result as shown in Table 2.

As can be seen from Table 2 , gratitude directly predicted self-esteem $(\beta=$ $0.444, p<0.001)$, gratitude directly predicted academic self-efficacy $(\beta=0.075, p$ $<0.05)$, and self-esteem directly predicted academic self-efficacy $(\beta=0.508, p<$ 0.001 ). When gratitude, self-esteem and academic self-efficacy simultaneously predicted core self-evaluations, gratitude, self-esteem and academic self-efficacy

Table 1. Means, standard deviations, and correlations among variables.

\begin{tabular}{lcccccc}
\hline \multicolumn{1}{c}{ Variables } & M & SD & 1 & 2 & 3 & 4 \\
\hline 1. Gratitude & 5.17 & 1.11 & 1 & & & \\
2. Self-esteem & 2.83 & 0.51 & $0.44^{* *}$ & 1 & & \\
3. Academic self-efficacy & 3.23 & 0.67 & $0.30^{* *}$ & $0.54^{* *}$ & 1 & \\
4. Core self-evaluations & 3.36 & 0.63 & $0.32^{* *}$ & $0.53^{* *}$ & $0.56^{* *}$ & 1 \\
\hline
\end{tabular}

Note: ${ }^{*} p<0.05,{ }^{* *} p<0.01,{ }^{* * *} p<0.001$. As the same below. 
Table 2. Regression analysis of variables in the model.

\begin{tabular}{ccccccc}
\hline Outcome variable & Predictor variable & $R$ & $R^{2}$ & $F$ & $\beta$ & $t$ \\
\hline Self-esteem & Gender & 0.443 & 0.196 & 74.609 & -0.076 & $-2.556^{*}$ \\
& Gratitude & & & & 0.444 & $14.930^{* * *}$ \\
Academic self-efficacy & Gender & 0.590 & 0.348 & 122.574 & 0.027 & 1.007 \\
& Grade & & & & -0.223 & $-8.370^{* * *}$ \\
& Gratitude & & & & 0.075 & $2.498^{*}$ \\
& Self-esteem & & & & 0.508 & $17.090^{* * *}$ \\
Core self-evaluations & Gender & 0.633 & 0.401 & 122.686 & -0.086 & $-3.346^{* *}$ \\
& Grade & & & & -0.048 & -1.814 \\
& Gratitude & & & & 0.094 & $3.263^{* *}$ \\
& Self-esteem & & & & 0.282 & $8.631^{* * *}$ \\
& Academic self-efficacy & & & & 0.372 & $11.746^{* * *}$ \\
\hline
\end{tabular}

had direct positive predictive effects on core self-evaluations $(\beta=0.094, p<$ $0.01 ; \beta=0.282, p<0.001 ; \beta=0.372, p<0.001)$. That is, self-esteem and academic self-efficacy have a partial mediating effect between gratitude and core self-evaluations of rural junior middle school students.

According to model 6 in the SPSS macro compiled by Hayes, the chain mediation test was performed, and the $95 \%$ confidence interval of the mediation effect was calculated by repeating 2000 times. The results are shown in Table 3. The study found that $95 \%$ of the mediating effects of self-esteem and academic self-efficacy between gratitude and core self-evaluations were respectively $(0.177$, $0.254)$ and $(0.007,0.504)$, excluding 0 , indicating that self-esteem and academic self-efficacy had significant mediating effects between gratitude and core self-evaluations. The $95 \%$ confidence interval $(0.058,0.094)$ of the chain mediating effect of self-esteem and academic self-efficacy doesn't include 0 , indicating that self-esteem and academic self-efficacy have a chain mediating effect between gratitude and core self-evaluations of rural junior middle school students. The chain mediating effect model is shown in Figure 1.

\section{Discussion}

This study finds that gratitude, as an important influencing factor for individual core self-evaluations, has a significant positive predictive effect on the core self-evaluations of rural middle school students. The research result is consistent with hypothesis 1 . That is, the core self-evaluations of rural junior middle school students obviously promoted with the increasing of the gratitude level. Gratitude is an indispensable factor to promote the youth development. Therefore, ensuring a good quality of gratitude can help rural junior middle school students to form a good interpersonal interaction model, which are more rational and peaceful in the process of interaction with others, get more social support (Wang $\& \mathrm{Wu}, 2020)$, and then show their recognition of their abilities and values. At the 


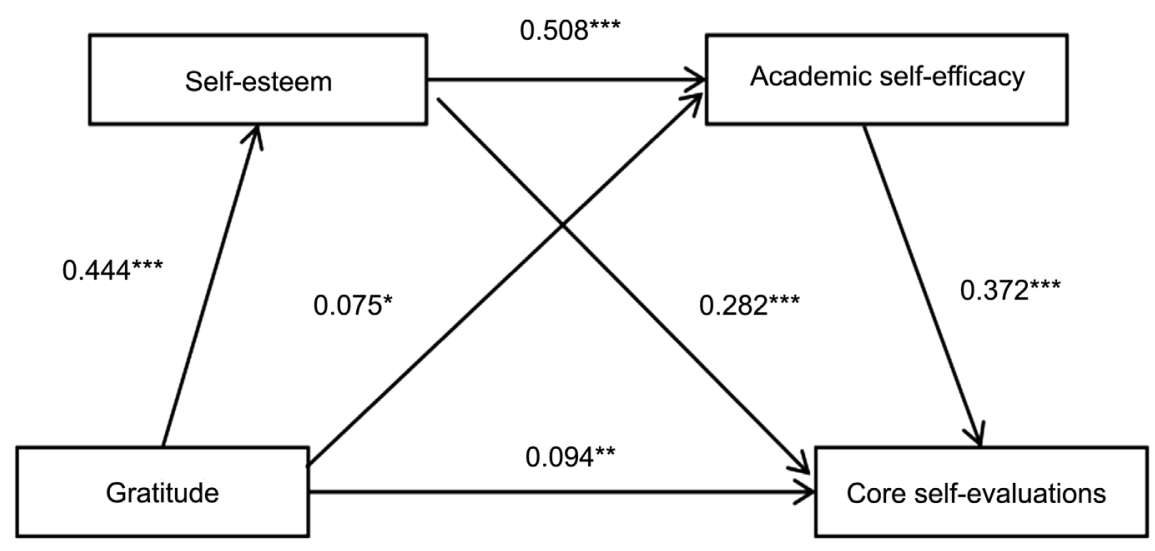

Figure 1. The chain mediating effect of self-esteem and academic self-efficacy between gratitude and core self-evaluations.

Table 3. The mediating effect test of self-esteem and academic self-efficacy between gratitude and core self-evaluations.

\begin{tabular}{cccc}
\hline Indirect effect & $\begin{array}{c}\text { Effect } \\
\text { value }\end{array}$ & $\begin{array}{c}\text { Effect } \\
\text { size }\end{array}$ & $\begin{array}{c}95 \% \text { confidence } \\
\text { interval interval }\end{array}$ \\
\hline $\begin{array}{c}\text { Gratitude } \rightarrow \text { Self-esteem } \rightarrow \text { Core self-evaluations } \\
\text { Gratitude } \rightarrow \text { Academic self-efficacy } \rightarrow \text { Core self-evaluations }\end{array}$ & 0.225 & $52.45 \%$ & $(0.177,0.254)$ \\
Gratitude $\rightarrow \begin{array}{c}\text { Self-esteem } \rightarrow \text { Academic self-efficacy } \\
\rightarrow \text { Core self-evaluations }\end{array}$ & 0.083 & $19.35 \%$ & $\quad(0.058,0.094)$ \\
Total mediation effect & 0.335 & $78.09 \%$ & \\
Direct effect & 0.094 & $21.91 \%$ & \\
The total effect & 0.429 & & \\
\hline
\end{tabular}

same time, gratitude can also activate, update and expand the scope and flexibility of rural junior middle school students' cognition (Song et al., 2018). On the one hand, it is good for helping them observe things more positively and adopting more active attributional pattern when faced with difficulties. On the other hand, pursuing the inner goal of success in their study and life has more expectations for their future development. Moreover, more appreciable with themselves and forming positive self-awareness, so rural junior middle school students promote their development of the core self-evaluations level.

Analysis of the mediating effect shows that gratitude will indirectly affect the core self-evaluations of rural junior middle school students through self-esteem and academic self-efficacy. Both of them play a chain mediating role between gratitude and core self-evaluations. First of all, self-esteem plays a mediating effect between gratitude and core self-evaluations in rural junior middle school students, which is consistent with hypothesis 2 . It shows that gratitude indirectly affected the core self-evaluations of rural junior middle school students by self-esteem. Gratitude is a kind of rich resources for individuals (e.g., interpersonal resources, psychological resources) (Fredrickson, 2001). It is conducive to adapt to campus life better in the process of learning and living and improve the 
ability to resist frustration for rural junior middle school students by enhancing self-awareness and recognition of self-worth and developing their self-esteem. If rural junior middle school students have a higher level of self-esteem, they will more positively evaluate themselves, and understand their own abilities and self-value more clearly (Liu et al., 2017), which is helpful to form a positive self-concept, thus improving the core self-evaluations of rural junior middle school students (Cheng, 2013). Secondly, academic self-efficacy plays a mediating role between gratitude and core self-evaluations in rural junior middle school students, which is consistent with Hypothesis 3. It also shows that gratitude indirectly affects the core self-evaluations of rural junior middle school students through their academic self-efficacy. Gratitude is generated with the help for others and is conducive for rural junior middle school students by helping others after experiencing gratitude emotional experience ( $\mathrm{Wu}$ et al., 2019), thus they are inclined to repay society and others. The best way for students to return to society is to study hard and achieve excellent academic results. Therefore, higher level of gratitude caused higher level of the academic self-efficacy. With the development of academic self-efficacy level, rural junior middle school students will build confidence in their own learning tasks (Yang, $\mathrm{Xu}$, \& Zheng, 2009), recognize learning attitudes, and learning abilities and are more willing to turn to teachers and classmates when encountering academic difficulties or academic failures, then form the positive learning strategy (Fan \& Williams, 2010). To a certain extent, it was enabled students to gain the recognition and increase self-confidence from their teachers and classmates, promoting their recognition of self-ability and self-worth. Finally, self-esteem and academic self-efficacy play a chain mediating role between rural junior middle school students' gratitude and core self-evaluations, which is consistent with Hypothesis 4 . The core self-evaluations of rural junior middle school students can further promote their academic self-efficacy by improving their self-esteem. The improvement of academic self-efficacy is conducive to the development of students' academic ability and behavior and the improvement of positive self-evaluation (Huang, 2015). Rural junior middle school students with high levels of gratitude can usually make a correct understandings of their abilities and values, experiencing their own value in time ( $\mathrm{Li} \& \mathrm{Liu}, 2018$ ), and forming a higher levels of self-esteem. On this basis, when they faced academic difficulties with a positive attitude will help those individuals to increase their confidence and interests in learning and form the strong sense of academic self-efficacy (Jia, 2012). When students have the ability to complete their own learning tasks, the self-confidence and initiative of learning will be increased. And with the adoption of coping strategies that actively solve problems, they can give full play to their potential and form a positive self-awareness, thereby promoting core self-evaluation developments among rural junior middle school students (Jiang, 2014), and better adapting to their learning and living environments.

This study of rural junior middle school students between gratitude and core self-evaluation mediation mechanism, not only proved that gratitude and core 
self-evaluation have a significant positive correlation, and further revealed the gratitude is affected the level of core self-evaluation through intermediary variable of rural junior middle school students, namely gratitude indirectly through the self-esteem and academic self-efficacy chain of intermediary role affect the level of core self-evaluation of rural junior middle school students. Therefore, self-esteem and academic self-efficacy play a key role in the relationship between gratitude and core self-evaluation of rural junior middle school students, which provides certain theoretical guidance for improving the level of core self-evaluation of rural junior middle school students. This enlightens rural junior middle schools in the process of cultivating junior middle school students to form a higher level of core self-evaluation. First of all, the direct role of gratitude should be paid attention. School can conduct psychological health education courses such as the theme lecture of gratitude and the group counseling of gratitude. Besides, school should also pay attention to carry out campus cultural activities with gratitude characteristics, and strive to build a grateful school, so as to improve students' level of gratitude. Further, school should pay attention to cultivate students' positive psychology, form a positive and optimistic attitude, so as to form a higher level of self-esteem. Besides, teachers should provide opportunities for students to fully display their various talents, especially in the learning of junior middle school students to give more active support, so that students have a sense of confidence in their own abilities in the learning process, and further improve students' sense of academic self-efficacy. Finally, improving the core self-evaluation level of rural junior middle school students as a whole. At the same time, the researches must be considered with the context of the limitations below. On the one hand, this study is a cross-sectional study, which is slightly less good at explaining the causal relationship between the four. Future studies can further investigate the causal relationship between them by combining with tracing. On the other hand, the object of this study is junior middle school students in rural areas. The validity of the research conclusion is low when it is extended to other groups, so different groups of subjects can be selected for research in the future.

\section{Conflicts of Interest}

The authors declare no conflicts of interest regarding the publication of this paper.

\section{References}

Abdollahi, A., \& Talib, M. A. (2015). Self-Esteem, Body-Esteem, Emotional Intelligence, and Social Anxiety in a College Sample: The Moderating Role of Weight. Psychology Health and Medicine, 21, 221-225. https://doi.org/10.1080/13548506.2015.1017825

Baumeister, R. F., Campbell, J. D., Krueger, J. I., \& Vohs, K. D. (2003). Does High Self-Esteem Cause Better Performance, Interpersonal Success, Happiness, or Healthier Lifestyles? Psychological Science in the Public Interest, 4, 1-44.

https://doi.org/10.1111/1529-1006.01431 
Chen, Q. Z. (2016). Study on the Relationship between Academic Procrastination and Academic Self-Efficacy of Junior Middle School Students. Journal of East China Normal University (Educational Sciences), 34, 100-106.

Cheng, L. L. (2013). A Comparative Study on Self-Concept and Mental Health between Obesity and Normal Weight Students in Junior Middle School. Occupational Health, 29, 1305-1308.

Dai, X. Y. (2010). Commonly Used Psychological Assessment Scale Manual (pp. 249-251). Beijing: People's Military Medical Press.

Fan, W., \& Williams, C. M. (2010). The Effects of Parental Involvement on Students' Academic Self-Efficacy, Engagement and Intrinsic Motivation Self-Efficacy, Engagement and Intrinsic Motivation. Educational Psychology, 30, 53-74.

https://doi.org/10.1080/01443410903353302

Fredrickson, B. L. (2001). The Role of Positive Emotions in Positive Psychology: The Broaden-and-Build Theory of Positive Emotions. American Psychologist, 56, 218-226. https://doi.org/10.1037/0003-066X.56.3.218

Fredrickson, B. L., \& Joiner, T. (2002). Positive Emotions Trigger Upward Spirals toward Emotional Well-Being. Psychological Science, 13, 172-175.

https://doi.org/10.1111/1467-9280.00431

Guo, J. C., \& Ye, Y. D. (2017). How Core Self-Evaluations Influences Life Satisfaction in Adolescents: The Mediating Effects of Hope. Studies of Psychology and Behavior, 15, 663-668.

Hou, J. Q. (2019). The Effect of Peer Rejection on Depressive Symptoms: The Chain Mediating Role of Gratitude and Self-Esteem. Chinese Journal of Special Education, 26, 35-39.

Huang, B. (2015). The Related Research, Sense of Self-Esteem and Peer Relationship of Academic Self Efficacy. Wuhan: South-Central University for Nationalities.

Jia, J. (2012). The Effects of Emotional Support from Teachers on Self-Esteem and Academic Self-Efficacy of Middle School Students. Chongqing: Southwest University.

Jiang, H. (2014). The Relationships among the Resilience, Core Self-Evaluation and Subjective Well-Being of Left-Behind Middle School Students in Rural and Its Corresponding Countermeasures. Kaifeng: Henan University.

Judge, T. A., \& Larsen, R. J. (2001). Dispositional Affect and Job Satisfaction: A Review and Theoretical Extension. Organizational Behavior and Human Decision Process, 86, 67-98. https://doi.org/10.1006/obhd.2001.2973

Judge, T. A., Locke, E. A., Durham, C. C., \& Kluger, A. N. (1998). Dispositional Effects on Job and Life Satisfaction: The Role of Core Evaluations. Journal of Applied Psychology, 83, 17-34. https://doi.org/10.1037/0021-9010.83.1.17

Lee, S., \& Jung, T. (2014). How Retaking the Entrance Examination Can Enhance Student Quality of Life at University. Social Behavior and Personality: An International Journal, 42, 331-340. https://doi.org/10.2224/sbp.2014.42.2.331

Li, D. P., Zhang, W., Li, X., Li, N. N., \& Ye, B. J. (2011). Gratitude and Suicidal Ideation and Suicide Attempts among Chinese Adolescents: Direct, Mediated, and Moderated Effects. Journal of Adolescence, 35, 55-66. https://doi.org/10.1016/j.adolescence.2011.06.005

Li, X., \& Liu, F. B. (2018). The Effect of Perceived Social Support on Life Satisfaction of People with Disabilities: The Mediating Role of Self-Esteem and the Moderating Role of Communication. Studies of Psychology and Behavior, 16, 141-146.

Lin, C. D. (2008). Developmental Psychology (pp. 320-321). Beijing: People's Education 
Press.

Liu, G. Z., Pan, Y. G., Li, W. W., Meng, Y. Y., \& Zhang, D. J. (2017). Effect of Self-Esteem on Social Anxiety in Adolescents: The Mediating Role of Self-Concept Clarity. Chinese Journal of Clinical Psychology, 25, 151-154.

Liu, Z. H. (2017). Migrant Children's Academic Values and School Well-Being: The Mediating Effect of Academic Self-Efficacy. Chinese Journal of Special Education, 24, 67-73.

Luo, J., Wu, D. P., Liu, Z. H., Jin, T. L., Yuan, F. Z., \& Qi, S. S. (2019). The Effect of Core Self-Evaluation on Freshmen Adaptation: The Mediating Effect of Achievement Motivation. Journal of Guizhou Normal University (Natural Sciences), 37, 95-100.

Lv, C. F., \& Zhou, Y. H. (2019). Relationship between Gratitude and Problem Behavior in Street Children: The Mediating Role of Core Self-Evaluations and Social Support. Chinese Journal of Clinical Psychology, 27, 406-409.

Qi, Y. H., \& Wei, X. Y. (2016). Analysis on the Relationship between Academic Self-Efficacy, Trait Hope and Resilience of Secondary Vocational School Students with Learning Excellence or Disability. Vocational and Technical Education, 37, 71-73.

Song, Y. Z., Tian, Y., Zhou, Z. K., Lian, L. S., \& Niu, G. F. (2018). The Impact of Belief in a Just World on Depression: The Serial Mediating Roles of Gratitude and Self-Esteem. Journal of Psychological Science, 41, 828-834.

Sudha, K. S. (2013). Core Self-Evaluations as a Correlate of Subjective Well-Being among Special Educators. Journal of the Indian Academy of Applied Psychology, 39, 83-89.

Wang, S. S., Liu, Y. J., \& Jackson, T. (2016). The Influence of Self-Esteem Level on Self-Assessment in University Students. Health Medicine Research and Practice, 13, 8-10.

Wang, W. C., \& Wu, X. C. (2020). Mediating Roles of Gratitude, Social Support and Posttraumatic Growth in the Relation between Empathy and Prosocial Behavior among Adolescents after the Ya'an Earthquake. Acta Psychologica Sinica, 52, 307-316.

Wei, X., Wu, H. T., Kong, X. N., \& Wang, H. T. (2011). Revision of Gratitude Questionnaire-6 in Chinese Adolescent and Its Validity and Reliability. Chin J Sch Health, 32, 1201-1202.

Wen, C., Zhang, W., Li, D. P., Yu, C. F., \& Dai, W. Z. (2010). Relationship between Junior Students Gratitude and Academic Achievement: With Academic Engagement as the Mediator. Psychological Development and Education, 26, 598-605.

Wen, Z. L., \& Ye, B. J. (2014). Analyses of Mediating Effects: The Development of Methods and Models. Advances in Psychological Science, 22, 731-745. https://doi.org/10.3724/SP.J.1042.2014.00731

Wu, R. H., Liu, W. F., \& Gao, M. (2017). The Intervention Effect of Group Counseling on Academic Self-Efficacy of Secondary Vocational School Students. Psychology: Techniques and Applications, 5, 762-768.

Wu, Z. H., Zhao, Z. F., Li, B. S., \& Lan, S. P. (2019). Effects of Gratitude Contemplation Intervention on Improving Life Satisfaction in College Students. Psychology: Techniques and Applications, 7, 665-670.

Xu, Y. (2019). Effect of Gratitude on Envy: The Chain Mediating Role of Social Support and Self-Efficacy. Changsha: Hunan Norman University.

Yang, Q., Yi, L. L., \& Song, W. (2016). Relation of Loneliness to Family Cohesion and School Belonging in Left-Behind Children. Chinese Mental Health Journal, 30, 197-201.

Yang, X. F., Xu, S. A., \& Zheng, X. (2009). A Study on the Relationship among Social Support, Core Self-Evaluation and Subjective Well-Being in College Students. Chinese 
Journal of Special Education, 19, 83-89.

Yang, Y., \& Wang, D. F. (2007). Retest of the Bidimensional Model of Rosenberg Self-Esteem Scale. Chinese Mental Health Journal, 21, 603-605.

Zeng, X. H. (2008). Relationship among Academic Self-Efficacy, Coping Styles and Mental Health of Senior School Students. Fuzhou: Fujian Norman University.

Zhang, Y. L., Li, S., \& Yu, G. L. (2019). The Relationship between Self-Esteem and Social Anxiety: A Meta-Analysis with Chinese Students. Advances in Psychological Science, 27, 1005-1018. https://doi.org/10.3724/SP.J.1042.2019.01005

Zhou, F. (2019). The Influence of Parental Rearing Patterns on Test Anxiety of Junior Middle School Students: The Mediating Role of Self-Esteem and Academic Self-Efficacy. Dalian: Liaoning Norman University.

Zhou, H., \& Long, L. R. (2004). Statistical Remedies for Common Method Biases. Advances in Psychological Science, 12, 942.

Zhou, Z., \& Han, Y. (2014). General Self-Efficacy of Special Education Teachers and Its Relation to Their Core Self-Evaluations. Teacher Education Research, 26, 55-60.

Zimmerman, B. J. (1995). Self-Efficacy and Educational Development. In A. Bandura (Ed.), Self-Efficacy in Changing Societies (pp. 202-231). New York: Cambridge University Press. https://doi.org/10.1017/CBO9780511527692.009 